\title{
The odyssey of the immigrant in American history: From the changed to the changer. A bibliographic essay
}

\section{Plummer Alston Jones Jr.}

To cite this article: Plummer Alston Jones Jr. (1988) The odyssey of the immigrant in American history: From the changed to the changer. A bibliographic essay, Immigrants \& Minorities, 7:3, 314-323, DOI: $10.1080 / 02619288.1988 .9974696$

To link to this article: https://doi.org/10.1080/02619288.1988.9974696

Published online: 21 Jun 2010.

Submit your article to this journal

山ll Article views: 9

View related articles $₫$ 


\title{
The Odyssey of the Immigrant in American History: From the Changed to the Changer. A Bibliographic Essay
}

\begin{abstract}
This essay examines the work of nine contemporary historians who have reacted to the model of immigration associated with the work of Oscar Handlin. Some of these writers have composed variations on Handlin's work: others have opposed it. Their findings and interpretations have profoundly altered the historiography of immigration into America.
\end{abstract}

Maldwyn Allen Jones, the eminent British historian, has aptly cited immigration as the historic raison d'être of America. The singularly poignant exception of the American Indians notwithstanding, Americans are, indeed, immigrants or, more frequently nowadays, their descendants. Immigration has thus been thoroughly and inextricably woven into the very fabric of American history and life with historians and chroniclers throughout the last three centuries faithfully describing the successive waves of immigrants: the earliest French and Spanish explorers and adventurers; the colonists and settlers of predominantly English, Dutch and Swedish stock; the 'old' immigrants from Germany and Ireland; the 'new' from Italy, Russia and Poland; and, now, the immigrants from Mexico, Central and South America, Canada and the Caribbean.

Despite the intermittent campaigns of nativists throughout the nineteenth century to halt the flow of immigration altogether and their ultimate success in limiting immigration from the Orient, the flow of immigrants from Europe continued unabated. As the flow increased dramatically at the turn of the twentieth century, the all-pervasive powers of bigotry and restrictionism, which had never truly subsided, combined with the outwardly respectable science of eugenics to sway public opinion toward a belief that immigrants of certain racial and ethnic groups were more desirable than others.

The Dillingham Commission, set up by the United States Congress in 1907 to study the immigration question, effectively played upon such widely held beliefs and called upon so-called experts to pronounce their judgments on the merits and demerits of unlimited immigration. The massive 41-volume treatise which resulted from the testimonies of these witnesses and other deliberations of the Commission provided the stimulus needed for the passage of immigration legislation which has since strictly limited immigration from southem and eastem Europe, Asia, and other parts of the globe except, significantly, the 
Western Hemisphere, the principal source of twentieth century immigration to America.

The imposition of immigration restrictions has, ironically, given historians of immigration since the 1920s a distinct advantage, a unique perspective afforded by distance in time and person from the phenomenon itself. Rather than being in the thick of tremendous migratory changes, these historians have written their accounts during a period when legal immigration, for all practical purposes, has been reduced to a mere trickle. Of these historians, Marcus Hansen and Oscar Handlin were the first to probe far beyond the usual questions treated by their colleagues of the seventeenth, eighteenth and nineteenth centuries, seeking to identify not only the origins of immigrants and their contributions to American society but also to trace common threads in the immigration experience and to demonstrate how the immigration phenomenon affected the immigrants themselves as well as the 'native' Americans.

Hansen in his The Immigrant in American History (Harvard University Press, 1940) began the process of distilling the various explanations for the international and national migration movements by identifying the westward movement, industrialization and urbanization as related phenomena. His writings develop around the interplay of these principal themes while exploring the relationships between and among immigration and a host of other social and cultural forces from Puritanism to democracy.

But it was Hansen's student, Oscar Handlin, who went a significant step further by creating a model, an ideal if you will, of the immigrant experience. Handlin's The Uprooted (Little, Brown, 1951), later revised although not substantively altered in 1973, presented distinctive ways of viewing the immigration phenomenon, so distinct in fact that they have preserved stereotypical, even mythical images of the immigrant in the mind of America.

For Handlin, immigration represented an abrupt, irreparable break with past traditions. The immigrant was separate from the mainstream of American society, isolated physically and socially, stripped of the comforts of past associations, bewildered, powerless, in short, the object rather than the agent of tumultuous change. Despite the convincing framework for the analysis of immigration which emerged, historians, particularly since 1960, have taken exception to, sought to modify, and, indeed, challenged the validity of Handlin's approach in dealing with fundamental issues relating to the very nature of the immigrant experience.

This bibliographic essay will examine the works of nine contemporary historians who have thus reacted to Handlin's model: some composing variations on Handlin's theme; others producing divergent counterpoints to it. Their findings and, to an equally important extent, their interpretations have significantly altered the historiography of immigration into America. 
Maldwyn Allen Jones in his American Immigration (University of Chicago Press, 1960) and Moses Rischin in his The Promised City: New York's Jews, 1870-1914 (Harvard University Press, 1962) have presented variations on Handlin's theme: the former treating the whole range of immigration history; the latter concentrating on the Eastem European Jewish experience at the tum of the twentieth century. Jones, who embraces Handlin's ideal, sees absolutely no reason to distinguish between immigrant groups since they were very similar in their reasons for emigration, in the financial resources and occupational skills they brought with them, and in their ability to adapt. Jones emphasizes that immigration as a social process has shown remarkably little variation throughout American history and that the immigration experience was indeed traumatic, as Handlin had asserted, so traumatic in fact that the immigrant felt himself to be a 'marginal man'. Jones goes beyond Handlin, however, in suggesting that this feeling of marginality was not without benefits, stimulating as it were an awareness within the immigrants of ethnic consciousness which, in turn, spurred them to abandon local and regional loyalties in favour of a sense of nationalism.

Rischin, too, finds no real quarrel with Handlin's model of change since it was appropriate at least to describe the experience of Eastem European Jews in New York City from 1870 to 1914, a period of mass immigration before the imposition of legal restrictions. Rischin emphasizes, however, that the Jews were driven from their homelands by political and religious persecution in addition to the economic pressures which motivated other immigrant groups. Furthermore, he shows that the immigrant experience was far from sterile or lonely.

The development of a vast array of educational, charitable, social and religious organizations was, according to Rischin, testament to the ethnic consciousness of Jewish immigrants and their ability to mobilize their communities for overall improvement. Occupationally and politically, however, the Jews diverged from the mainstream, due in no small measure to discrimination they encountered in the society at large. The establishment of the United Hebrew Trades and the ardent support of Jewish immigrants for socialism as a political ideology were examples of their unique, if somewhat unorthodox, responses to the pressures of American trade unionism and politics.

John Higham's Send These to Me: Jews and Other Immigrants in Urban America (Atheneum, 1975) represents yet another variation on Handlin's model, but with a significant twist. Higham differentiates immigrants by their order of arrival, that factor determining ethnic status. That status has, in turn, been shaped by the skills and propensities each group brought with it to America and by the strategies each group evolved to meet the challenge of later arrivals. Higham sees immigrants as agents of change, willing to band together to achieve occupational and political advancement, but still remaining independent in inter-personal matters of family, religion and culture. 
Within Higham's work, we find the seeds of a new approach, a model based on continuity rather than change.

By the late 1970s and early 1980s, the seeds apparent in Higham's pivotal work have blossomed into a new school of thought which totally disregards Handlin's model of change as not only inappropriate to explain the diversity and variety in the immigrant experience, but also contrary to factual evidence. Five seminal works embracing this new historical model appear: three isolating the experience of Italian immigrants; one the experience of second-generation Jewish Americans; and another comparing the Russian Jewish and Italian immigrant experiences. The three works dealing with the Italian immigrants will be treated first, beginning with Virginia Yans-McLaughlin's Family and Community: Italian Immigrants in Buffalo, 1880-1930 (University of Illinois Press, 1982, c.1977).

Yans-McLaughlin, who takes exception to the clear-cut dichotomy between European and American urban societies of Handlin's model, stresses rather that social change can occur without the dissolution of traditional forms. On the contrary, she presents a quite provocative thesis that, in the case of Italian immigrants, change did not entail the adoption of entirely new ways, but rather an adaptation of old, familiar ones.

Yans-McLaughlin explains that those Italians who saw emigration as merely a way to avoid the loss of status and to fulfill an inherent desire to own property were, at least initially, interested only in earning enough money in the United States to return to Italy and purchase land. This observation was confirmed by her study of the Italian immigrants in Buffalo who sought good wages as opposed to careers that required a permanent attachment to the New World.

Kinship and family life played extremely important roles in the lives of Italian immigrants. Extended family ties worked not only to help newcomers find housing and employment, but also to help other family members in Italy to join them in America.

Thus, Italians were more family-centred than community-centred. This inordinant reliance on the family, often referred to as amoral familism, worked to place responsibility for the welfare of the family on the father as ultimate head, rather than on outside social agencies. The positive effects of such an arrangement included the virtual absence of broken homes and illegitimacy but, on the negative side, produced a distrust of welfare agencies, even the Catholic Church, which could have ameliorated their financial and social burdens.

Yans-McLaughlin attributes these and other characteristics of Italian immigrants, such as an underemphasis on the importance of education for children and an inability to organize politically, to premigration pattems established in Italy where their experience with social welfare agencies and politics was limited. Consequently, public welfare agencies in this country, including the public schools, failed in their missions to reach the Italian immigrants and significantly alter 
their life-styles. Unions also were slow in attracting Italians who faced much of the discrimination as the Jews in Rischin's study.

In sum, Yans-McLaughlin found ample evidence among Italian immigrants in Buffalo to justify her conclusion that the adult-centred, familistic life styles, with strict sex role differentiation characteristic of Italian families, as well as their occupational patterns, were attributes inherited from the Old World and continued in the New.

John Walker Briggs takes a similar approach in his An Italian Passage: Immigrants to Three American Cities, 1890-1930 (Yale University Press, 1978). Briggs, like Yans-McLaughlin, eschews the stories of immigrant exploitation and discrimination in favour of looking at immigrants as active agents, possessing a viable culture and the ability to initiate change and adaptation. He emphasizes that immigration as a selective process was concerned with those individuals who wished to better their conditions, those endowed with what it takes to succeed in difficult, if not perilous, situations.

Briggs, unlike Yans-McLaughlin, however, found Italian immigrants in Rochester, Utica and Kansas City as already well-experienced with societies and associations supporting the bourgeois values of individual advancement through hard work, thrift, education and the acquisition of property. Indeed, these immigrants found this part of their Old World view entirely compatible with what they found in these American communities. Briggs offers evidence that immigrants rejected Old World attachments, maintained by frequent retum trips to Italy, only when they discovered that social advancement in Italy was impossible for them.

As Italians, in the three cities studied by Briggs, found new opportunities for personal mobility, education increasingly became an important commodity in the mobility ideology. Adding insight to the observation introduced in Yans-McLaughlin regarding the reliance of Italian families on the income of their progeny for the welfare of the family as a whole, Briggs points out, quite correctly, that this practice was not a characteristic distinct to Italian immigrant families alone; it was an American working-class tradition.

In conclusion, Briggs places special emphasis on the areas of agreement between Italian immigrants and the American communities they entered. The failure of historians to recognize such similarities has led many to credit immigrant progress to the American environment alone, rather than to intrinsic capabilities within the immigrants themselves. Ultimately, according to Briggs, it is only through the further study of those educational institutions which shape, perpetuate and transfer culture that we may hope to understand the lasting influences of immigrants on American society.

The final author of the trio studying Italian immigrants is Dino Cinel. His From Italy to San Francisco: The Immigrant Experience (Stanford University Press, 1982) adds a new dimension to those revealed in Yans-McLaughlin and Briggs in his concentration not only on the 
experiences of Italian immigrants in this country but also on the experiences of the over 50 per cent who eventually retumed to Italy. He shows that overseas migration from Italy began as a simple altemative to internal short-distance migrations Italians endured, and had grown to depend on, during long periods of unemployment and underemployment. Like Briggs, Cinel stresses that retum migration ended only when immigrants discovered that such temporary migration could not cure long-term social and economic problems in Italy; in fact, the dream of eventual retum even thwarted their progress in America initially. Italian immigrants in San Francisco, the focus of Cinel's study, were often content with positions low in the occupational hierarchy because these positions did not require education or prerequisite skills.

Cinel brings to our attention valuable insights into the complexities of the Italian immigrant community and its organization. Agreeing with Yans-McLaughlin that Italians were family-centred, he shows how that dependence slowly gave way to a feeling of regionalism, as Italians from the same regions of Italy became more socially and economically integrated. This loyalty to regionalism eventually evolved into a sense of nationalism, but it was a slow, deliberate process despite the efforts of the Catholic Church and the immigrant press to hasten it. Disagreeing with Briggs, however, Cinel demonstrates that immigrants had no experience in Italy with voluntary organizations and an aversion to them was transferred to the New World.

The most enduring legacy of Cinel's work lies in the understanding engendered conceming the effects of immigrants' experiences in this land as well as in their native lands. Cinel proves that the most unexpected force for change in the lives of Italian immigrants in San Francisco was the failure of retum migration efforts.

Deborah Dash Moore's study of second-generation Jewish Americans, At Home in America: Second Generation New York Jews (Columbia University Press, 1981), represents a very different approach from the other authors, with the possible exceptions of Higham and Jones, in that she focuses not on the immigrant generation per se, but on their children. For Jewish Americans, it was this second generation that consolidated a synthesis of American and Jewish values, values that for their parents were often very separate, as Rischin has pointed out.

The crux of her work deals with the interaction of Jewish middleclass ethnicity with forms of urban community. Jews tumed to their neighbourhoods to translate what Jewishness meant into a tangible reality. They chose residential concentration in large cities such as New York because of the urban virtues offered there, primarily convenience and access to culture and social opportunities. In the process, Jews acquired the psychological attitude of a majority in a country where they were a small minority.

Such Jewish associationalism supported by these middle-class urban neighbourhoods gave birth to a variety of ethnic expressions including, 
but not limited to, extensive occupational ties in the construction and housing industries; a fervent, even passionate advocacy of the separation of church and state in school-related issues; and support of civil liberties issues of all types. For their parents, socialism had been Judaism secularized; for second-generation Jewish Americans, it was and still is, to a great extent, liberalism.

Thomas Kessner's The Golden Door: Italian and Jewish Immigrant Mobility in New York City, 1880-1915 (Oxford University Press, 1977) weaves together many of the disparate threads of thought presented in the works of Briggs, Yans-McLaughlin, Cinel and Moore. He sees his work as a reaction to former studies, including Handlin's, which purported to show that immigrants, except for a few select individuals, were not occupationally mobile. Kessner presents documentary evidence to the contrary. Russian Jews and Italians were both able to tap the resources offered them in New York at the turn of the twentieth century to become not only occupationally, but also residentially, mobile.

Kessner also stresses difference between the two immigrant groups, the variety as well as the similarity. Italian immigration was primarily from southern Italy and consisted of unskilled single males who were often illiterate and without sufficient capital. Their goals for emigration were short-term in that most hoped to retum to Italy. Most Italians entered the work force at a low rung of the occupational ladder, to use Kessner's terminology, that of the unskilled manual labourer.

Russian Jews, on the other hand, came in family groups, brought urban skills gained in innkeeping, crafts and peddling, and settled with the intention of staying. These skills, particularly suited to many openings in the garment trade and other small industries, allowed Jewish immigrants to enter the occupational ladder at its middle rungs, those of the skilled and semi-skilled workers.

In other ways, these groups were different, each way affecting their mobility in American society. Jews were more community-centred, which translated into the development of voluntary educational, cultural and welfare agencies as well as trade unionism. Italians were more family-centred. Education was an economic as well as an aesthetic tool for Jews; for Italians, an irrelevant prolonging of childhood and, thus, a hindrance to wage eaming.

Second-generation Italian and Jewish offspring differed in patterns of mobility as well. Italians persisted in jobs similar to those held by their parents and tended to live in the same segregated neighbourhoods. Jewish offspring, reared to exceed their parents' achievements, moved into higher-level white-collar jobs and better neighbourhoods.

Kessner found the ghetto life-style not a barrier to mobility, a concept which Handlin's ideal espoused, but rather a 'mobility launcher'. Jews and Italians, even those who did not move into higherlevel jobs, found it easy to move to other cities. Both immigrant groups were residentially mobile as well, opening up new ethnic neighbour- 
hoods in Manhattan as well as other boroughs, notably Brooklyn and the Bronx. As new job skills were acquired and as income levels rose, those who could afford better accommodations moved to find them. For reasons of job proximity and for personal reasons, however, many chose to remain in their original neighbourhoods longer, the point being that a definite choice was involved.

Thus far, the works examined have presented variations on or modifications to Handlin's ideal as well as completely different and divergent alternatives to it. The ninth and final work to be treated in this bibliographical essay, as well as the most recent, John Bodnar's The Transplanted: A History of Immigrants in Urban America (Indiana University Press, 1985), while drawing upon Handlin's concept of the ideal immigrant experience, presents a totally new model. Bodnar's new model is based on the thesis that what immigrant groups shared in common was not a tumultuous process of transformation beyond their power to resist, but rather a need to confront a new economic order, capitalism, and to provide for their own welfare and that of their kin. Each immigrant group did this, but each in its own different way and each with its own divergent results.

Bodnar shows how two manifestations of capitalism, manufactured goods and commercial agriculture, served as agents which precipitated emigration from some regions and not others, depending on when they apeared. The first to leave, a minority of the immigrant population, were those farmers and craftsmen threatened by the drive to acquire large estates suitable for the production of cash crops and by the advent of cheaply-produced manufactured wares. These emigrants wished to avoid a decline in status, usually possessed some capital, left in family groups, and were less likely to return. The second group to confront the challenge of capitalism, and by far the majority of the immigrant population, was composed of owners of land and their children, or those who owned no land at all. This group of emigrants consisted more of individuals than family units, those who hoped to acquire enough resources in the New World to achieve a more respectable status as selfsufficient land owners or craftsmen when they returned to their native lands.

Bodnar's classification of immigrant groups resembles Kessner's description of the Jews and Italians respectively, with the exception that the Jews were not legally allowed to own property. Regardless of their classification, however, all emigrants implied in the very act of their emigration that they were attempting to deal with capitalism and to survive at all costs, rather than remaining in the native land, relying solely on past habits and facing almost certain impoverishment. Bodnar calls our attention to the fact, lest we forget it, that many peasants, indeed, chose the latter altemative.

Bodnar agrees with all the authors treated thus far that families and households were the predominant forms in which all immigrants ordered their lives and confronted the industrial American society. 
Familial and communal networks eased the transition in finding suitable housing and employment. These family networks would remain predominant among working-class families until the labour market was reshaped after the Second World War and skills, credentials and educational background gained more importance in entering new professions.

Immigrants were not a single, united mass of humanity, Bodnar reminds us. They were, like the society at large, fragmented into numerous enclaves classified by status, ideology and cultural orientation. This realization supports Bodnar's suspicion that immigrant response to capitalism was conditioned less by group culture or even by American urban, economic and cultural structures, and more by the interaction of those classes, ideologies and cultures within and outside of the immigrant communities.

Bodnar stresses that, to a large extent, the status of an immigrant in his homeland would play an important role in determining his status in the structure of American industrial capitalism, a fact suggesting that inequality within and among immigrant groups often originated from an inherited status. In time, however, a new immigrant middle class arose which was often divided in its loyalties to the immigrant community, sometimes abandoning kin for better occupational opportunities and better neighbourhoods. However, if such elevated status depended on the support of the larger immigrant community for its maintenance, those of the middle class would maintain a closer relationship as well as attempt to use their influence in shaping community opinion and action.

Ultimately, immigrants' lives were not tied to spatial settlements and buildings but to jobs and families, an understanding of the immigrant situation which Bodnar shares with Kessner. When the job changed or income improved, even the ghetto could not confine immigrants as they moved on in search of better opportunities elsewhere.

For the immigrants, it was neither religious traditions nor ethnic solidarity that motivated them, but the ideals of Americanization, hard work, thrift and free enterprise, a concept Bodnar and Briggs share. Echoing a theme common to the works of Briggs, Cinel and YansMcLaughlin, Bodnar stresses that public institutions and voluntary agencies which wanted the participation of immigrants could have it, but only on a limited basis and on terms the immigrants themselves viewed as beneficial.

Surprisingly as well, the Church was not an agent of cohesion amidst all the turmoil, a point supported by Cinel, Briggs and YansMcLaughlin; in fact, Bodnar concludes that no institution in immigrant America exhibited more discord and division. The more religious leaders laboured to centralize authority within the immigrant community, the more secular leaders would agitate for increased ethnic consciousness and nationalism. Such fragmentation, of course, left immigrant attitudes divided and, according to Bodnar, actually ensured 
that the immigrant communities would not last. Immigrants consequently made a conscious decision that their futures would be decided in their families, unions, and even political parties, institutions where a greater degree of consensus was possible.

For Bodnar, therefore, the mentality and culture of most immigrants to urban America were a blend of past and present and always centred on the immediate and the attainable. Immigrants were not resourceless and indecisive but, to the contrary, were resourceful and pragmatic.

From Handlin to Bodnar, we have witnessed a bibliographical odyssey of the immigrant in American history. For many immigrant groups, Handlin's model of change will never be supplanted since his model has captured essential truths, especially for such immigrant groups as the Jews for whom long-term immigration was the only altemative. For other immigrant groups, the Italians for example, the model of continuity is more appropriate since this group could and did retum to their homeland without any extraordinary difficulty, a process reinforcing Old World ways and keeping them alive longer in American immigrant communities. But it is Bodnar's ideal of commonality, a collective and yet individual response to the allpervasive challenge of capitalism, which offers the most provocative framework to date for understanding the immigrant experience in America.

Only time will tell which historical approach will endure. All authors discussed would naturally testify to the continuing need for more research on this important aspect of our national history. Undoubtedly, all future histories will reflect the cumulative wisdom of these authors and present the immigrant not as changed by, but rather as a changer of American society.

PLUMMER ALSTON JONES, Jr. Elon College, NC 